\title{
A RISK SCREENING STUDY ON THE POTENTIAL INVASIVENESS OF LESSEPSIAN FISHES IN THE SOUTH-WESTERN COASTS OF ANATOLIA
}

\author{
Gökçen BILGE ${ }^{1 *}$, Halit FILIZ ${ }^{1}$, Sercan YAPICI ${ }^{1}$, A. Serhan TARKAN ${ }^{1,2}$, and Lorenzo VILIZZI² \\ ${ }^{1}$ Muğla Sttkı Koçman University, Faculty of Fisheries, Department of Basic Sciences, Muğla, Turkey \\ ${ }^{2}$ Department of Ecology and Vertebrate Zoology, Faculty of Biology and Environmental Protection, \\ University of Łódź, Łódź, Poland
}

Bilge G., Filiz H., Yapici S., Tarkan A.S., Vilizzi L. 2019. A risk screening study on the potential invasiveness of Lessepsian fishes in the south-western coasts of Anatolia. Acta Ichthyol. Piscat. 49 (1): 23-31.

\begin{abstract}
Background. The 'Lessepsian migration' is a unidirectional phenomenon of successful biotic colonisation from the Red Sea into the eastern Mediterranean Sea via the Suez Canal. In this study, 45 Lessepsian marine fish species were screened for their potential invasiveness in the south-western coasts of Anatolia (Muğla region, Turkey), with the aim to inform policy makers on proper management and control measures.

Materials and methods. Species were screened with the Aquatic Species Invasiveness Screening Kit (AS-ISK) for their potential invasiveness in the south-western coasts of Anatolia - the Risk Assessment (RA) area. Receiver Operating Characteristic (ROC) analysis was used to assess the predictive ability of AS-ISK to discriminate between the Lessepsian fish species posing a high risk and those posing a medium risk of being invasive for the RA area. The following species were studied: Alepes djedaba, Apogonichthyoides pharaonis, Atherinomorus forskalii, Bregmaceros nectabanus, Callionymus filamentosus, Champsodon nudivittis, Champsodon vorax, Cynoglossus sinusarabici, Dussumieria elopsoides, Equulites klunzingeri, Etrumeus golanii, Fistularia commersonii, Hemiramphus far, Herklotsichthys punctatus, Jaydia queketti, Jaydia smithi, Lagocephalus guentheri, Lagocephalus sceleratus, Lagocephalus spadiceus, Lagocephalus suezensis, Liza carinata, Nemipterus randalli, Ostorhinchus fasciatus, Oxyurichthys petersii, Parupeneus forsskali, Pelates quadrilineatus, Pempheris rhomboidea, Pomadasys stridens, Pteragogus pelycus, Pterois miles, Rachycentron canadum, Sargocentron rubrum, Saurida lessepsianus, Scomberomorus commerson, Siganus luridus, Siganus rivulatus, Sillago suezensis, Sphyraena chrysotaenia, Sphyraena flavicauda, Stephanolepis diaspros, Torquigener flavimaculosus, Trachurus indicus, Upeneus moluccensis, Upeneus pori, Vanderhorstia mertensi.

Results. BRA and BRA + CCA thresholds of 18.5 and 29.5, respectively, were identified that reliably distinguished between potentially invasive (high risk) and potentially non-invasive (medium or low risk) species. Based on both thresholds, 14 species were categorised as high risk (amongst which devil firefish, Pterois miles, was the highestscoring one), 28 as medium risk, and one as low risk. The CCA resulted in an increase from the BRA score for 42 $(93.3 \%)$ of the screened species, and 12 of these achieved the highest possible (positive) change in BRA + CCA score of 12 points.

Conclusion. The thresholds set in the presently reported study for risk of invasiveness of the Lessepsian fishes under study in the south-western coasts of Anatolia can be transferred to other AS-ISK based applications in other RA areas in case of small sample sizes. The outcomes of this study will be of use to fish biologists, fisheries scientists and environmental managers/stakeholders in a joint effort to ensure better conservation and management actions with regard to the role of Lessepsian fishes in the RA area.
\end{abstract}

Keywords: Pterois miles, Muğla coasts, AS-ISK, Suez Canal, global warming

\section{INTRODUCTION}

The Mediterranean Sea is an important biodiversity hotspot that has been increasingly subject to multiple anthropogenic threats including overfishing, non-native species invasions, and climate change (Kletou et al. 2016). Also, rise in seawater temperatures, compounded with the establishment and spread of non-native (invasive) species, has caused community shifts and tropicalisation (Lejeusne et al. 2010, Montefalcone et al. 2015). Currently, it is estimated that nearly 1000 non-native aquatic species (Zenetos 2017, Zenetos et al. 2017), the majority of which thermophilic, have entered the eastern basin of the Mediterranean Sea through the Suez Canal (Katsenevakis et al. 2014), and this trend is expected to increase in the future (Galil et al. 2015). 
The 'Lessepsian migration', which has been Fistularia commersonii Rüppell, 1838; Hemiramphus defined as a unidirectional phenomenon of successful far (Forsskål, 1775); Herklotsichthys punctatus (Rüppell, biotic colonisation from the Red Sea into the eastern 1837); Jaydia queketti (Gilchrist, 1903); Jaydia smithi Mediterranean Sea via the Suez Canal (Por 1978), is an ongoing process responsible for both positive and negative effects on the marine ecosystem (Farrag et al. 2016). In total, 165 non-indigenous marine fish species have been reported for the entire Mediterranean Sea as having entered from both the Red Sea (via the Suez Canal) and the Atlantic Ocean (via the Strait of Gibraltar) (Anonymous 2017). More than half of these species $(n=85)$ have so far been recorded from Turkey, and 45 of them currently occur along the coasts of south-western Anatolia (Muğla Province) (Bilge et al. 2017, Filiz et al. 2017a). Of the 85 non-indigenous marine fish species (51 families in total), 75 are of Indo-Pacific, nine of Tropical Atlantic and one of Boreal Atlantic origin (Filiz et al. 2017a). As a matter of additional concern, some Lessepsian fish species can be poisonous and have traumatogenic, especially neurotoxic (e.g., devil firefish, Pterois miles*; dusky spinefoot, Siganus luridus; marbled spinefoot, Siganus rivulatus; yellow spotted puffer, Torquigener flavimaculosus) and histamine-related (e.g., narrow-barred Spanish mackerel, Scomberomorus commerson) effects on humans.

The aim of this study was to determine the potential invasiveness of Lessepsian fishes in the south-western coasts of Anatolia (Muğla Province, Turkey) and to assess whether predicted global warming conditions may enhance further their dispersal. For this purpose, a recently-developed, generic risk screening tool for aquatic species was employed to provide a preliminary evaluation of the Lessepsian fishes that may cause ecological and economic impacts in the study area. It is anticipated that the presently reported findings will provide a first step towards the successful management of the potentially invasive Lessepsian fish species in the south-western coasts of Anatolia, hence pose a threat to the native marine ecosystems. This knowledge is essential for the management and conservation of the local native marine fish faunas and related fisheries.

\section{MATERIAL AND METHODS}

Risk screening. In total, 45 Lessepsian fish species recorded from the south-western coasts of Anatolia (Table 1), hereafter the Risk Assessment (RA) area, were screened for their potential invasiveness. The following species were studied: Alepes djedaba (Forsskål, 1775); Apogonichthyoides pharaonis (Bellotti, 1874); Atherinomorus forskalii (Rüppell, 1838); Bregmaceros nectabanus Whitley, 1941; Callionymus filamentosus Valenciennes, 1837; Champsodon nudivittis (Ogilby, 1895); Champsodon vorax Günther, 1867; Cynoglossus sinusarabici (Chabanaud, 1931); Dussumieria elopsoides Bleeker, 1849; Equulites klunzingeri (Steindachner, 1898); Etrumeus golanii DiBattista, Randall et Bowen, 2012;

Kotthaus, 1970; Lagocephalus guentheri Miranda Ribeiro, 1915; Lagocephalus sceleratus (Gmelin, 1789); Lagocephalus spadiceus (Richardson, 1845); Lagocephalus suezensis Clark et Gohar, 1953; Liza carinata (Valenciennes, 1836); Nemipterus randalli Russell, 1986; Ostorhinchus fasciatus (White, 1790); Oxyurichthys petersii (Klunzinger, 1871); Parupeneus forsskali (Fourmanoir et Guézé, 1976); Pelates quadrilineatus (Bloch, 1790); Pempheris rhomboidea Kossmann et Räuber, 1877; Pomadasys stridens (Forsskål, 1775); Pteragogus pelycus Randall, 1981; Pterois miles (Bennett, 1828); Rachycentron canadum (Linnaeus, 1766); Sargocentron rubrum (Forsskål, 1775); Saurida lessepsianus Russell, Golani et Tikochinski, 2015; Scomberomorus commerson (Lacepède, 1800); Siganus luridus (Rüppell, 1829); Siganus rivulatus Forsskål et Niebuhr, 1775; Sillago suezensis Golani, Fricke et Tikochinski, 2013; Sphyraena chrysotaenia Klunzinger, 1884; Sphyraena flavicauda Rüppell, 1838; Stephanolepis diaspros Fraser-Brunner, 1940; Torquigener flavimaculosus Hardy et Randall, 1983; Trachurus indicus Nekrasov, 1966; Upeneus moluccensis (Bleeker, 1855); Upeneus pori Ben-Tuvia et Golani, 1989; Vanderhorstia mertensi Klausewitz, 1974. Notably, the species assessed, despite having been often recorded in the RA area, are not yet naturalised therein. Following previous ASISK applications on fishes (Glamuzina et al. 2017, Li et al. 2017, Tarkan et al. 2017a, 2017b), to achieve an objective a priori categorisation of the species assessed in terms of their perceived invasiveness (i.e., invasive or non-invasive), which is a requirement for ROC analysis (see Statistical analysis), each species' categorisation was initially derived from two independent sources, namely the Invasive Species Specialist Group database (ISSG**) and FishBase (Froese and Pauly 2018). However, the initial classification was regarded as unsatisfactory for the purposes of the presently reported study as all the Lessepsian fishes assessed are currently listed in FishBase or ISSG either as 'harmless' (hence, carrying no risk of invasiveness) or 'not yet evaluated', and none of them is included in the Global Invasiveness Species Database $\left(\mathrm{GISD}^{* * *}\right)$. For this reason, a priori classification was carried out by the first three authors, based on records in the available documentation for the RA area (Tuncer et al. 2008, Aydin 2011, Uyan et al. 2016, Filiz et al. 2017c).

The Aquatic Species Invasiveness Screening Kit (AS-ISK v1 $1^{* * * *}$ ) (Copp et al. 2016) was used to identify potentially invasive species with respect to the RA area. AS-ISK includes the generic screening module of the European Non-native Species in Aquaculture Risk Analysis Scheme (ENSARS) (Copp et al. 2016), whilst incorporating the 'minimum requirements' (Roy et al.

\footnotetext{
All names (with the authority of the year) of fishes covered by this study are listed in Materials and methods.

"* http://www.issg.org.

*** http://www.iucngisd.org/gisd/.

${ }^{* * * * *}$ Available for free download at https://www.cefas.co.uk/nns/tools/.
} 


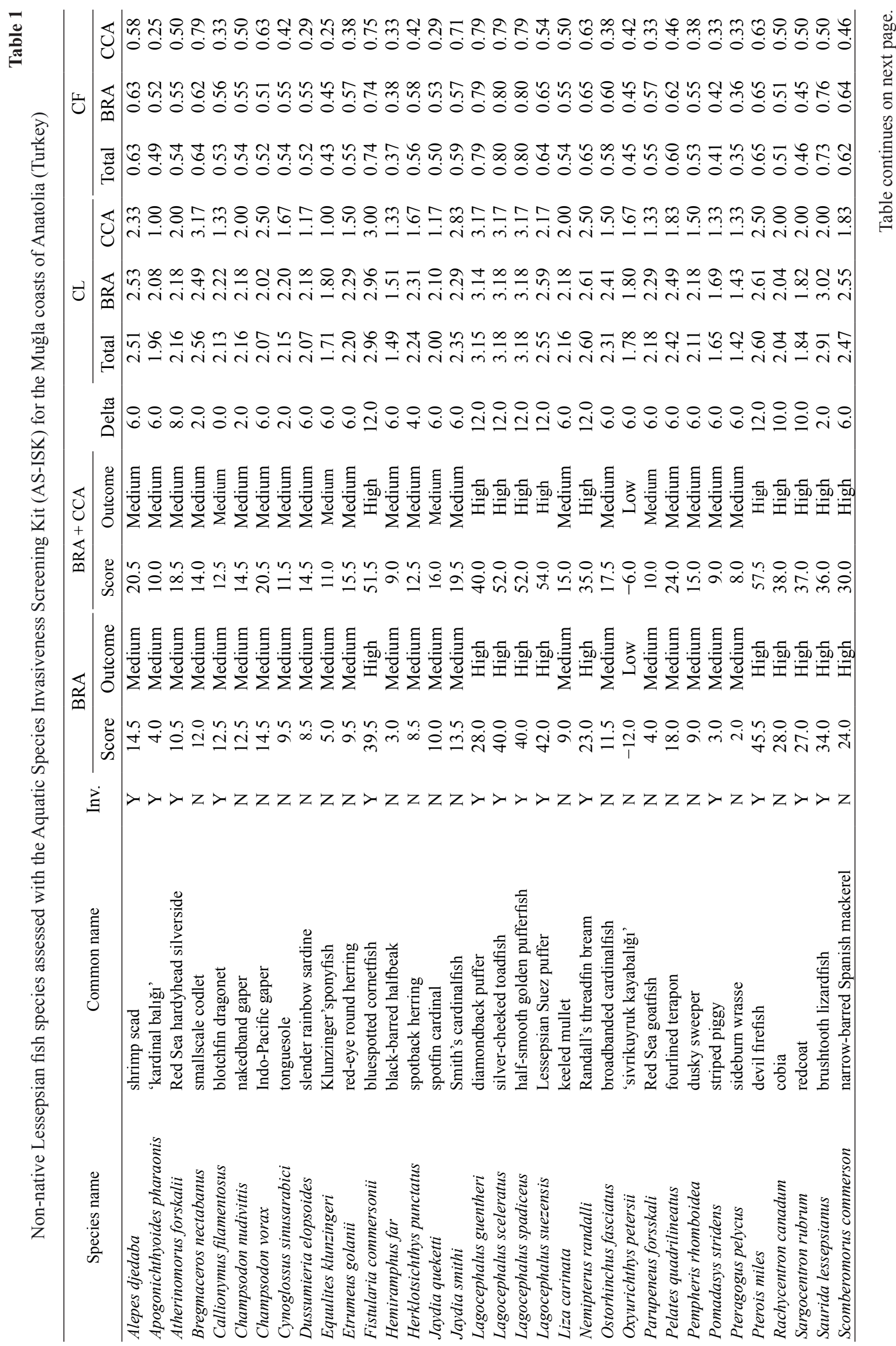


2014) for the assessment of non-native invasive species with regard to the recent EC Regulation on the prevention and management of the introduction and spread of invasive alien species (Anonymous 2014). AS-ISK consists of 55 questions in total. The first 49 questions cover the biogeographical/historical (Section 1) and biological/ ecological (Section 2) aspects of the species under assessment, and these comprise the Basic Risk Assessment (BRA); the remaining six questions require the assessor to predict how future climatic conditions are likely to affect the BRA with respect to risks of introduction, establishment, dispersal, and impact, and these represent Section 3 of the Climate Change Assessment (CCA). For each question, the assessor must provide a response, justification and level of confidence (see below), and the screened species eventually receives both a BRA and a BRA + CCA (composite) score (respectively ranging, theoretically, from -20 to 68 and from -32 to 80 ). ASISK scores $<1$ suggest that the species is unlikely to become invasive in the RA area, and is therefore classified as 'low risk'; on the contrary, higher score values categorise the species as posing either a 'medium risk' or a 'high risk' of becoming invasive. Distinction between medium and high risk levels depends upon definition of a 'threshold' value, which is typically obtained through RA area-specific 'calibration' provided the availability of a representative sample size (i.e., number of screened species). Finally, the ranked levels of confidence $(1=$ low, 2 out of 10 chances; 2 = medium, 5 out of $10 ; 3=$ high, 8 out of $10 ; 4=$ very high, 9 out of 10) associated with each question-related response in AS-ISK mirror the confidence rankings recommended by the International Programme on Climate Change (Metz et al. 2005, Copp et al. 2016).

Statistical analysis. Following computation of the BRA and BRA + CCA scores, Receiver Operating Characteristic (ROC) analysis (Bewick et al. 2004) was used to assess the predictive ability of AS-ISK to discriminate between the Lessepsian fish species posing a high risk and those posing a medium risk of being invasive for the RA area. Statistically, a ROC curve is a graph of sensitivity vs. 1- specificity (or alternatively, sensitivity vs. specificity), where in the present context sensitivity and specificity will be the proportion of invasive and non-invasive Lessepsian fish species, respectively, that are correctly identified as such by AS-ISK. A measure of the accuracy of the calibration analysis is the Area Under the Curve (AUC), which typically ranges from 0.5 to 1.0 , and the closer to 1.0 the better the ability of AS-ISK to differentiate between invasive and non-invasive species (Tarkan et al. 2017a, 2017b). Following ROC analysis, the best AS-ISK threshold value that maximises the true positive rate (i.e., a priori invasive species classified as invasive, hence 'true positives') and minimises the false positive rate (i.e., a priori non-invasive species classified as invasive, hence 'false positives') was determined using Youden's J statistic. Whereas, the 'default' threshold of 1 was set to distinguish between low risk and medium risk species (see Risk screening). Notably, a priori non- 
invasive species classified as non-invasive will be 'true negatives', and a priori invasive species classified as noninvasive will be 'false negatives'.

ROC analysis was carried out with package pROC (Robin et al. 2011) for R x64 v3.0.3 (R Core Team 2018) using 2000 bootstrap replicates for the confidence intervals of specificities, which were computed along the entire range of sensitivity points (i.e. 0 to 1 , at 0.1 intervals), and with the addition of a smoothed mean ROC curve. Based on the confidence levels allocated to each response for a given species (see Risk screening), an overall confidence factor $\left(\mathrm{CF}_{\text {Total }}\right)$ was computed as

$$
\frac{\sum(\mathrm{CQ} i)}{(4 \times 55)}(i=1, \ldots, 55)
$$

where $\mathrm{CQ}_{i}$ is the confidence level (CL) for Question $i$ $(\mathrm{Q} i), 4$ is the maximum achievable value for certainty (i.e., 'very certain') and 55 is the total number of questions comprising the AS-ISK tool. The $\mathrm{CF}_{\text {Total }}$ therefore ranges from a minimum of 0.25 (i.e., all 55 questions with certainty score equal to 1 ) to a maximum of 1 (i.e., all 55 questions with confidence level equal to 4). Two additional confidence factors were also computed for the BRA and CCA questions, namely the $\mathrm{CF}_{\mathrm{BRA}}$ and the $\mathrm{CF}_{\mathrm{CCA}}$, based on 49 Qs (Sections 1 and 2) and 6 Qs (Section 3), respectively.

Differences between mean confidence level and mean confidence factor for the BRA $\left(\mathrm{CL}_{\mathrm{BRA}}, \mathrm{CF}_{\mathrm{BRA}}\right)$ and $\mathrm{CCA}\left(\mathrm{CL}_{\mathrm{CCA}}, \mathrm{CF}_{\mathrm{CCA}}\right)$ were tested by permutational analysis of variance (PERANOVA) based on a one-factor design (Component, with the two levels BRA and CCA). Analysis was performed in PERMANOVA+ for PRIMER v6, with normalisation of the data and using a Bray-Curtis dissimilarity measure, 9999 unrestricted permutations of the raw data (Anderson et al. 2008), and with statistical effects evaluated at $\alpha=0.05$.

\section{RESULTS}

The ROC curves for the BRA and BRA + CCA resulted in an AUC of $0.8095(0.6686-0.9504,95 \% \mathrm{CI})$ and of 0.8026 (0.6602-0.9449, 95\% CI), respectively (Fig. 1A, 1B). These AUCs were well above 0.5, indicating that AS-ISK was able to discriminate reliably between non-invasive and invasive Lessepsian fishes for the RA area. Youden's $J$ provided a threshold of 18.5 for the BRA and of 29.5 for the BRA + CCA, which were used for calibration of the AS-ISK risk outcomes. Accordingly, the BRA threshold allowed to distinguish between medium risk species with scores within the interval $\left[1,18.5{ }^{*}\right.$ and high risk species with scores within $] 18.5,68]$; the BRA + CCA threshold allowed to distinguish between medium risk species with scores within [1,29.5[ and high risk species with scores within $] 29.5,80]$. Finally, species classified as low risk were those with BRA scores within $[-20,1[$ and BRA + CCA scores within $[-32,1[$.

Based on both the BRA and BRA + CCA thresholds, $14(35.6 \%)$ of the 45 screened species were classified as high risk, $28(62.2 \%)$ as medium risk, and the remaining one $(2.2 \%)$ as low risk (Table 1). All 14 species categorised a priori as invasive were (correctly) classified as high risk; amongst the species categorised a priori as non-invasive, 'sivrikuyruk kayabalığı', Oxyurichthys petersii, was (correctly) classified as low risk (hence, true negative), whereas $S$. commerson and cobia Rachycentron canadum were classified as high risk (hence, false positives); and, no a priori invasive species was classified as low risk (cf. false negatives). Finally, 21
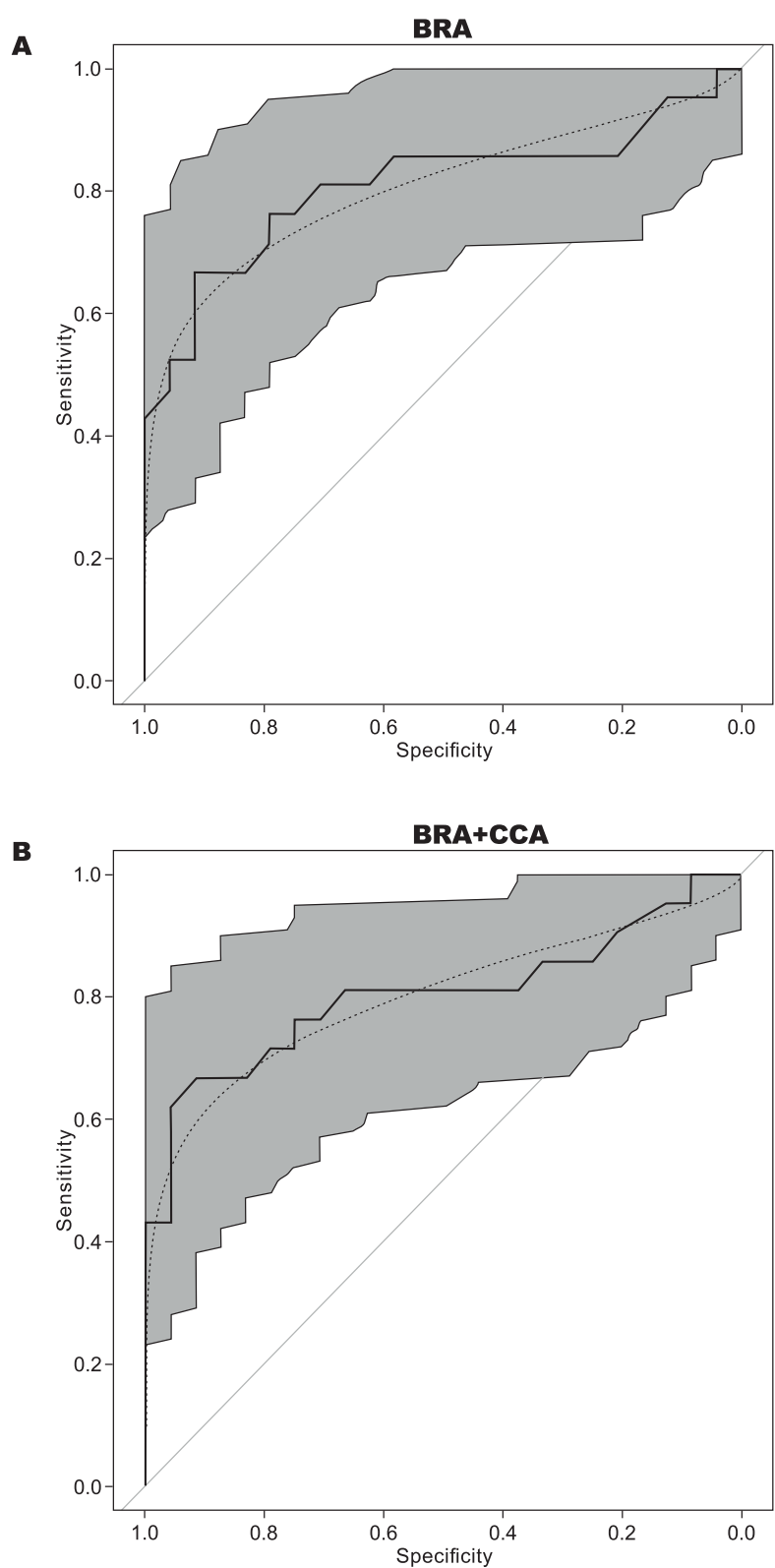

Fig. 1. (A) Receiver Operating Characteristic (ROC) curve (solid line) for the Basic Risk Assessment (BRA) on the 45 Lessepsian fish species screened with the Aquatic Species Invasiveness, Screening Kit (AS-ISK) for the south-western coasts of Anatolia (Muğla Province, Turkey) (see also Table 1); smoothing line and confidence intervals of specificities are also provided; (B) Same for the Climate Change Assessment (CCA) 
a priori non-invasive and seven a priori invasive species were classified as medium risk (Table 1).

For both the BRA and the BRA + CCA, the highestscoring species (score $\geq 39.5$ for the BRA, chosen as an empirical, very high-risk 'sub-threshold') were P. miles; half-smooth golden pufferfish, Lagocephalus spadiceus; silver-cheeked toadfish, Lagocephalus sceleratus; Lessepsian Suez puffer, Lagocephalus suezensis; and bluespotted cornetfish, Fistularia commersonii (and with the second to fourth species in the list achieving the same score); whereas, the only low risk species was $O$. petersii, which achieved BRA and BRA + CCA scores well below the threshold of 1 (Table 1).

The CCA resulted in an increase from the BRA score for $42(93.3 \%)$ of the screened species; whereas, for the remaining three species there was no change between BRA and BRA + CCA score, and for no species did the BRA + CCA score result in a decrease relative to the BRA. Also, there were twelve species that achieved the highest possible (positive) change in score of 12, whereas this difference ranged from 2 to 10 (in increments of 2) for the remaining 30 species (Table 1).

Mean confidence level for all Qs $\left(\mathrm{CL}_{\text {Total }}\right)$ was $2.358 \pm$ $0.071 \mathrm{SE}$, for the BRA Qs $\left(\mathrm{CL}_{\mathrm{BRA}}\right) 2.404 \pm 0.072 \mathrm{SE}$, and for the CCA Qs $\left(\mathrm{CL}_{\mathrm{CCA}}\right) 1.989 \pm 0.094 \mathrm{SE}$, hence in all cases within the 'high' category. However, the mean $\mathrm{CL}_{\mathrm{BRA}}$ was significantly higher than the mean $\mathrm{CL}_{\mathrm{CCA}}\left(F_{1,88}^{\#}=10.96\right.$, $P=0.001)$. Similarly, mean values for $\mathrm{CF}_{\text {Total }}=0.590 \pm$ $0.018 \mathrm{SE}$ and $\mathrm{CF}_{\mathrm{BRA}}=0.601 \pm 0.018 \mathrm{SE}$ were higher than the $\mathrm{CF}_{\mathrm{CCA}}=0.497 \pm 0.024 \mathrm{SE}$, and the mean $\mathrm{CF}_{\mathrm{BRA}}$ was significantly higher than the mean $\mathrm{CF}_{\mathrm{CCA}}\left(F_{1,88}^{\#}=10.96\right.$, $P=0.001)$.

\section{DISCUSSION}

In the first extensive application of AS-ISK to marine fishes (cf. Filiz et al. 2017b, 2017c), approximately one third of the screened species were classified as posing a high to very high risk potential of becoming invasive in the south-western coasts of Anatolia.

The highest-scoring species in this study, namely $P$. miles, is currently considered to be one of the most successful marine invaders in the history of aquatic invasions (Filiz et al. 2017b). Two major introduction pathways have been suggested for this species, namely (i) through the Suez Canal, similar to several other marine organisms (Zenetos et al. 2012), and (ii) following release from captivity (Golani et al. 2002). Considering that $P$. miles is widespread throughout the Red Sea and in the proximity of the Suez Canal, the latter represents the species' main pathway of introduction into the Mediterranean Sea (Bariche et al. 2013). Pterois miles first appeared in the eastern Mediterranean Sea at about the same time that its $P$. volitans/miles complex (of IndoPacific origin) was first reported off the coasts of Florida, where it has since spread rapidly and colonised almost all warm parts of the east coast of the United States, Gulf of Mexico, and the Caribbean Sea (Schofield et al. 2016). On the contrary, more than two decades have elapsed since the second sighting of this species in the Mediterranean
Sea (Filiz et al. 2017b). However, the possibility of $P$. miles invasion in the latter, including the potential ecological and socio-economic impacts that may follow, have been so far largely neglected (Filiz et al. 2017b).

The invasion by pufferfishes (which BRA-scores between 28.0 and 42.0 indicated high invasiveness potential: see Table 1) in the Mediterranean Sea has resulted in substantial ecological and socio-economic impacts. As mentioned in Turan et al. (2016), increasing temperatures in the Mediterranean Sea likely due to climate change have provided for more suitable habitat conditions to pufferfishes, especially in terms of reproduction. Besides climate change effects, the recent increase in abundance and expansion of pufferfishes in the eastern Mediterranean Sea appears to have been favoured by the presence of few natural predators combined with the species' ability to adapt to a range of new habitats, to the point that substantial impacts on local ecosystems and fisheries are now expected (Filiz et al. 2017c). Likely due to their being poisonous and locally quite abundant, pufferfishes have been reported to cause negative effects on fisheries, including damage to fishing gears, overall loss of catches (especially of $L$. sceleratus) and replacement of commercially important species (Anonymous 2010). Also, Indo-Pacific pufferfishes contain tetrodotoxin, which is a known non-protein organic compound (aminoperhydroquinazoline) and one of the strongest marine paralytic toxins (Halstead 1978). Tetrodotoxin can be found in the liver, gonads, intestines, and skin of these fish and is responsible for death from intoxication in $\approx 60 \%$ of the cases in humans (Ellenhorn and Barceloux 1988). The dramatic invasion success of pufferfishes is thought to have resulted from a combination of factors including early maturation and reproduction, anti-predatory poisonous defences and ecological versatility, coupled with the availability of native prey and overfishing of (potential) native predators (Côté et al. 2013, Filiz et al. 2017c).

The last highest-scoring species $F$. commersonii is considered to be one of the most invasive species in the Mediterranean Sea, with the most important environmental parameters responsible for its distribution including mean depth, chlorophyll- $a$ and salinity. In this respect, coastal areas with relatively low chlorophyll- $a$ concentrations and high salinities have been found to be the preferred habitat for F. commersonii in its invasive range; whereas, very high productivity, low salinities and cold temperatures represent together abiotic resistance factors to invasion (Azzurro et al. 2013). It is expected that climate-change predicted variation in salinity, productivity and temperature in the Mediterranean Sea due to global climate change (Caddy et al. 1995, Briand 2008) could increase the suitability of this area for F. commersonii, with consequent increase in niche overlap with native species, which would in turn favour further expansion of its invasive range of distribution (Azzurro et al. 2013).

Amongst the other high-risk species, brushtooth lizardfish, Saurida lessepsianus, and Klunzinger's ponyfish, Equulites klunzingeri, were the most common fish species (out of 20 in total, accounting for $82.5 \%$ of 
the entire Lessepsian fish catch) recorded from a bottom trawling campaign in the Levant and Aegean Seas (Bilecenoğlu 2016). Also, whilst increased sea surface temperatures during the last century (and especially since the early 1990s) is believed to be one of the major causes for the establishment of alien species, the combined effects of other drivers such as deepening and widening of the Suez Canal, damming of the Nile River, gradual extinction of physical barriers through the Canal (cf. salinity), overall faunal impoverishment in the Levant Basin as well as overfishing along the eastern Mediterranean coasts, should also not be neglected (Galil 2006, Edelist et al. 2013). Whereas, to date no scientific studies are available on the only species (i.e., O. petersii) that was classified in the presently reported study as posing a low risk of being invasive for the RA area.

Computationally, the expert-based a priori categorization of the Lessepsian fishes screened for invasiveness in the presently reported study led to the miscategorization of only one species (i.e., the false positive S. commerson). Overall, this outcome is remarkable given that the expert-based a priori categorization for the screened species adopted in the presently reported study was an inescapable requirement of the limited knowledge available about the invasiveness status of Lessepsian fishes at the global level. Pending further applications, this may also indicate an overall high level of accuracy (i.e., larger proportion of true vs. false negatives and of true vs. false positives) of the AS-ISK tool for the screening of marine fishes in general. Also, it is argued that the thresholds set in the presently reported study for the Lessepsian fishes of the Muğla coastal areas of Turkey may be transferred to other AS-ISK based applications in other RA areas in case of small sample sizes preventing identification of RA-area specific thresholds based on local calibration. Whereas, at the wider scale, the thresholds identified in the presently reported study will contribute to refinement of global thresholds for marine fishes in general.

\section{ACKNOWLEDGEMENTS}

This research was supported by the Muğla Sıtkı Koçman University Scientific Research Funds (BAP 09/053, BAP 09/061, BAP 09/220 and BAP 09/259).

\section{REFERENCES}

Anderson M.J., Gorley R.N., Clarke K.R. 2008. PERMANOVA for PRIMER: Guide to software and statistical methods. PRIMER-E, Plymouth, UK.

Anonymous 2010. Report of the sub-regional technical meeting on the Lessepsian migration and its impact on eastern Mediterranean fishery. Nicosia, Cyprus, 7-9 December 2010. GCP/INT/041/EC-GRE-ITA. FAO_EastMed Project, Athens, Greece.

Anonymous 2014. Turkey progress report. European Commission. http:/lec.europa.eu/enlargement/pdf/ key_documents/2014/20141008-turkey-progressreport_en.pdf
Anonymous 2017. CIESM atlas of exotic fishes in the Mediterranean Sea. [Accessed on 5 October 2017.] http://www.ciesm.org/atlas/appendixl.html

Aydın M. 2011. Growth, reproduction and diet of pufferfish (Lagocephalus sceleratus Gmelin, 1789) from Turkey's Mediterranean Sea Coast. Turkish Journal of Fisheries and Aquatic Sciences 11 (4): 569576. DOI: 10.4194/1303-2712-v11_4_10

Azzurro E., Soto S., Garofalo G., Maynou F. 2013. Fistularia commersonii in the Mediterranean Sea: Invasion history and distribution modeling based on presence-only records. Biological Invasions 15 (5): 977-990. DOI: 10.1007/s10530-012-0344-4

Bariche M., Torres M., Azzurro E. 2013. The presence of the invasive lionfish Pterois miles in the Mediterranean Sea. Mediterranean Marine Science 14 (2): 292-294. DOI: $10.12681 / \mathrm{mms} .428$

Bewick V., Cheek L., Ball J. 2004. Statistics review 8: Qualitative data-Tests of association. Critical Care 8: 46-53. DOI: $10.1186 / \mathrm{cc} 2428$

Bilecenoğlu M. 2016. Demersal Lessepsian fish assemblage structure in the northern Levant and Aegean seas. Journal of Black Sea/Mediterranean Environment 22 (1): 46-59.

Bilge G., Filiz H., Yapıcı S., Tarkan A.S. 2017. How can be decided the true invasion potential: Applying Aquatic Species Invasiveness Screening Kit (AS-ISK) for Lessepsian fishes. P. 22. In: Tarkan A.S., Top N., Karakuş U., Sunar M. (eds.) II. Workshop on Invasive Species-Global meeting on invasive ecology, Bodrum, Turkey, 27-29 September 2017.

Briand F. (ed.) 2008. Climate warming and related changes in Mediterranean marine biota. CIESM Workshop Monographs No. 35. CIESM, Monaco.

Caddy J.F., Refk R., Do-Chi T. 1995. Productivity estimates for the Mediterranean: Evidence of accelerating ecological change. Ocean and Coastal Management 26 (1): 1-18. DOI: 10.1016/09645691(95)00015-T

Copp G.H., Vilizzi L., Tidbury H., Stebbing P.D., Tarkan A.S., Miossec L., Goulletquer P. 2016. Development of a generic decision-support tool for identifying potentially invasive aquatic taxa: AS-ISK. Management of Biological Invasions 7 (4): 343-350. DOI: $10.3391 / \mathrm{mbi} .2016 .7 .4 .04$

Côté I.M., Green S.J., Hixon M.A. 2013. Predatory fish invaders: Insights from Indo-Pacific lionfish in the western Atlantic and Caribbean. Biological Conservation 164: 50-61. DOI: 10.1016/j. biocon.2013.04.014

Edelist D., Rilov G., Golani D., Carlton J.T., Spanier E. 2013. Restructuring the sea: Profound shifts in the world's most invaded marine ecosystem. Diversity and Distributions 19 (1): 69-77. DOI: 10.1111/ddi.12002

Ellenhorn M.J., Barceloux D.G. 1988. Medical toxicology: Diagnosis and treatment of human poisoning. Elsevier Science Publishing Company, New York NY, USA. 
Filiz H., Ergüden D., Yapıcı S., Bilge G. 2017a. NonIndigenous Marine Fishes Along the Turkish Marine Waters: 2017 Revision. P. 28. In: Tarkan A.S., Top N., Karakuş U., Sunar M. (eds.) II. Workshop on Invasive Species-Global meeting on invasive ecology, Bodrum, Turkey, 27-29 September 2017.

Filiz H., Tarkan A.S., Bilge G., Yapıcı S. 2017 b. Assessment of invasiveness potential of Pterois miles by the Aquatic Species Invasiveness Screening Kit. Journal of Black Sea/Mediterranean Environment 23 (1): 17-37.

Filiz H., Yapıcı S., Bilge G. 2017c. The factors increasing of invasiveness potential of five pufferfishes in the eastern Mediterranean, Turkey. Natural and Engineering Sciences Supplement 2 (3): 22-30.

Farrag M.M.S., El-Haweet A.A.K., Akel E.-S.A., Moustafa M.A. 2016. Occurrence of puffer fishes (Tetraodontidae) in the eastern Mediterranean, Egyptian coast-Filling in the gap. BioInvasions Records 5 (1): 47-54. DOI: 10.3391/bir.2016.5.1.09

Froese R., Pauly D. (eds.) 2018. FishBase. [Version 06/2018] http://www.fishbase.org

Galil B.S. 2006. The marine caravan-The Suez Canal and the Erythrean invasion. Pp. 207-300. DOI: 10.1007/978-1-4020-5047-3_6 In: Gollasch S., Galil B.S., Cohen A.N. (eds.) Bridging divides; Maritime canals and invasion corridors. Monographiae Biologicae 83, Springer, Dordrecht, the Netherlands. DOI: 10.1007/978-1-4020-5047-3

Galil B.S., Boero F., Campbell M.L., Carlton J.T., Cook E., Fraschetti S., Gollasch S., Hewitt C.L., Jelmert A., Macpherson E., Marchini A., McKenzie C., Minchin D., Occhipinti-Ambrogi A., Ojaveer H., Olenin S., Piraino S., Ruiz G.M. 2015. 'Double trouble': the expansion of the Suez Canal and marine bioinvasions in the Mediterranean Sea. Biological Invasions 17 (4): 973-976. DOI: 10.1007/s10530-0140778-y

Glamuzina B., Tutman P., Nikolić V., Vidović Z., Pavličević J., Vilizzi L., Copp G.H., Simonović P. 2017. Comparison of taxon-specific and taxon-generic risk screening tools to identify potentially invasive nonnative fishes in the River Neretva catchment (Bosnia and Herzegovina and Croatia). River Research and Applications 33 (5): 670-679. DOI: 10.1002/rra.3124

Golani D., Orsi-Relini E., Massuti E., Quignard J.-P. 2002. CIESM Atlas of Exotic Species in the Mediterranean. Vol. 1. Fishes. CIESM Publishers, Monaco.

Halstead B.W. 1978. Poisonous and venomous marine animals of the world. Darwin Press, Princeton NJ, USA.

Katsanevakis S., Coll M., Piroddi C., Steenbeek J., Ben Rais Lasram F., Zenetos A., Cardoso A.C. 2014. Invading the Mediterranean Sea: Biodiversity patterns shaped by human activities. Frontiers in Marine Science 1: e32. DOI: 10.3389/fmars.2014.00032

Kletou D., Hall-Spencer J.M., Kleitou P. 2016. A lionfish (Pterois miles) invasion has begun in the
Mediterranean Sea. Marine Biodiversity Records 9: e46. DOI: 10.1186/s41200-016-0065-y

Lejeusne C., Chevaldonné P., Pergent-Martini C., Boudouresque C.F., Pérez T. 2010. Climate change effects on a miniature ocean: The highly diverse, highly impacted Mediterranean Sea. Trends in Ecology and Evolution 25 (4): 250-260. DOI: 10.1016/j. tree.2009.10.009

Li S., Chen J., Wang X., Copp G.H. 2017. Invasiveness screening of non-native fishes for the middle reach of the Yarlung Zangbo River, Tibetan Plateau, China. River Research and Applications 33 (9): 1439-1444. DOI: $10.1002 /$ rra.3196

Metz B., Davidson O., de Coninck H., Loos M., Meyer L. (eds.) 2005. IPCC species report on carbon dioxide capture and storage. Cambridge University Press, Cambridge, UK.

Montefalcone M., Morri C., Parravicini V., Bianchi C.N. 2015. A tale of two invaders: Divergent spreading kinetics of the alien green algae Caulerpa taxifolia and Caulerpa cylindracea. Biological Invasions 17 (9): 2717-2728. DOI: 10.1007/s10530-015-0908-1

Por F.D. 1978. Lessepsian migration, the influx of Red Sea biota into the Mediterranean by way of the Suez Canal. Ecological Studies book series Vol. 23. Springer-Verlag, Berlin, Heidelberg, New York. DOI: 10.1007/978-3-642-66728-2

R Core Team 2018. R: A language and environment for statistical computing. R Foundation for Statistical Computing, Vienna, Austria. https://www.R-project. org/

Robin X., Turck N., Hainard A., Tiberti N., Lisacek F., Sanchez J.-C., Müller M. 2011. pROC: an opensource package for $\mathrm{R}$ and $\mathrm{S}+$ to analyze and compare ROC curves. BMC Bioinformatics 12: e77. DOI: 10.1186/1471-2105-12-77

Roy H.E., Peyton J., Aldridge D.C., Bantock T., Blackburn T.M., Britton R., Clark P., Cook E., Dehnen-Schmutz K., Dines T., Dobson M., Edwards F.O., Harrower C., Harvey M.C., Minchin D., Noble D.G., Parrott D., Pocock M.J.O., Preston C.D., Roy S., Salisbury A., Schönrogge K., Sewell J., Shaw R.H., Stebbing P., Stewart A.J.A., Walker K.J. 2014. Horizon scanning for invasive alien species with the potential to threaten biodiversity in Great Britain. Global Change Biology 20 (12): 3859-3871. DOI: $10.1111 / \mathrm{gcb} .12603$

Schofield P.J., Morris J.jr., Langston J., Fuller P. 2016. Pterois volitans/miles FactSheet. USGS Nonindigenous Aquatic Species Database online Gainesville, FL. [Accessed on 03 February 2017.] http://nas.er.usgs. gov/queries/FactSheet.aspx?speciesID $=963$

Tarkan A.S., Sarı H.M., İlhan A., Kurtul I., Vilizzi L. 2017a. Risk screening of non-native and translocated freshwater fish species in a Mediterranean-type shallow lake: Lake Marmara (West Anatolia). Zoology in the Middle East 63 (1): 48-57. DOI: 10.1080/09397140.2017.1269398 
Tarkan A.S., Vilizzi L., Top N., Ekmekçi F.G., Stebbing P.D., Copp G.H. 2017b. Identification of potentially invasive freshwater fishes, including translocated species, in Turkey using the Aquatic Species Invasiveness Screening Kit (AS-ISK). International Review of Hydrobiology 102 (1-2): 47-56. DOI: 10.1002/iroh.201601877

Tuncer S., Aslan Cihangir H., Bilecenoglu M. 2008. First record of the Lessepsian migrant Lagocephalus spadiceus (Tetraodontidae) in the Sea of Marmara. Cybium 32 (4): 347-348.

Turan C., Erguden D., Gürlek M. 2016. Climate change and biodiversity effects in Turkish Seas. Natural and Engineering Sciences 1 (2): 15-24.

Uyan U., Filiz H., Top N., Tarkan A.S. 2016. Assessment of invasiveness potential of Nemipterus randalli in Mediterranean Sea by Aquatic Species Invasiveness Screening Kit (AS-ISK). P. 62. In: Tarkan A.S., Ekmekçi F.G., Uludağ A., Göç Rasgele P. (eds.) Uluslararası Katılımlı Sucul Türlerde Risk Belirleme Araçları Çalıştayı, Bildiriler Kitabi; Workshop on Risk Assessment Tools in Aquatic Species, Proceedings 28-29 April 2016, Düzce, Turkey, Pelin Ofset, Ankara, Turkey.
Zenetos A. 2017. Progress in Mediterranean bioinvasions two years after the Suez Canal enlargement. Acta Adriatica 58 (2): 347-358.

Zenetos A., Çinar M.E., Crocetta F., Golani D., Rosso A., Servello G., Shenkar N., Turon X., Verlaque M. 2017. Uncertainties and validation of alien species catalogues: The Mediterranean as an example. Estuarine, Coastal and Shelf Science 191: 171-187. DOI: 10.1016/j.ecss.2017.03.031

Zenetos A., Gofas S., Morri C., Rosso A., Violanti D., García Raso J.E., Çinar M.E., Almogi-Labin A., Ates A.S., Azzurro E., Ballesteros E., Bianchi C.N., Bilecenoglu M., Gambi M.C., Giangrande A., Gravili C., Hyams-Kaphzan O., Karachle P.K., Katsanevakis S., Lipej L., Mastrototaro F., Mineur F., Pancucci-Papadopoulou M.A., Ramos Esplá A., Salas C., San Martín G., Sfriso A., Streftaris N., Verlaque M. 2012. Alien species in the Mediterranean Sea by 2012. A contribution to the application of European Union's Marine Strategy Framework Directive (MSFD). Part 2. Introduction trends and pathways. Mediterranean Marine Science 13 (2): 328-352. DOI: $10.12681 / \mathrm{mms} .327$

Received: 13 March 2018 Accepted: 22 November 2018 Published electronically: 15 March 2019 